pox Hospital with a discrete attack. The mother was found to have had a nodified attack of small-pox, which had not been diagnosed.

2. A girl aged twelve, seen on suspicion, was found to be suffering from a very mild attack of small-pox. No medical man had been consulted. The father refused to admit that it was small-pox. She was removed to the hospital. Two other cases subsequently occurred in the same house.

3. This case has no direct bearing on the point in question, but is of interest otherwise. $\mathrm{E}$. $\mathrm{S}-$, aged fifteen, was removed suffering from modified small-pox. M. S__ was also removed, believed by me to be suffering from chickenpox, and was vaccinated. The vaccination took, and she did not contract small-pox. One of these girls had small-pox and the other chicken-pox exactly a fortnight after a previous case had developed what the medical attendant regarded, no doubt correctly, as chicken-pox. There is some evidence that chicken-pox cases become more numerous when an outbreak of small-pox is beginning, and it has been thought possible that some connexion existed between them. The above experience shows that chickenpox is radically distinct from small-pox, and also how easy it would have been either to lraw a false conclusion as to the connexion or to misjudge the nature of these two very distinct eruptions.

4. A man aged thirty-two contracted a modified attack of small-pox, which was undiagnosed, and led, as far as could be ascertained, to three persons contracting small-pox from him-a child, a friend who visited at his house, and a female operative working in the same room with him. His attack was ascertained from seeing the friend, but he had distinct marks of the eruption, with a history of the initial illness of small-pox. He was removed to the hospital and placed among small-pox patients without contracting the disease. These particulars are given because the case was denied to be one of small-pox.

5. The next case is that of five patients moved from one liouse not above 400 yards from the Small-pox Hospital. Four of these had occurred about the same time, and I satisfied myself that it was almost impossible that they could all have been exposed together to infection at any meeting outside the house. The hospital then came under review. But I fortunately examined the aged grandmother, and found that she had distinct marks of what had been a very mild, evidently modified attack of small-pox. A clear history was also given of the initial illness, which, however, had not been severe. No medical man had been consulted about the grandmother.

6. A woman aged twenty-one had a modified attack of small-pox. They refused to admit that it was small-pox, and said that a medical man, consulted after the one who reported the case, denied that it was small-pox. A case of a child occurred about the same time two doors off. Passing from one house to the other was a young man, who had one or two marks of small-pox on him, and gave a clear history of initial illness a fortnight previously, with eruption twodays after. The child of the first case subsequently took unmodified small-pox and died.

7. Three cases were reported to me of children who had not been under a medical man. In all only the marks of eruption without scabs remained. In two the distribution of the marks and their varying size indicated chicken-pox. In the third only one or two marks were found, but there were none on the chest, and an initial illness had occurred two days before the eruption came out. The case was, no doubt, one of small-pox, modified by vaccination, which had been orerlooked.

These examples will suffice to show that it is no mere chimera that the amelioration of small-pox by primary vaccination is liable to become a factor in the propagation of the disease, in the absence of the renewal of protection. To what extent it will be so depends on the character of the people, and on the amount of experience of all the medical men of any given district. The remedy, to a great extent, lies in the extension of compulsory notification, which, in $m y$ opinion, should rest mainly in the hands of medical men. I should not, however, like to say that if there were no vaccination we should altogether escape these difficulties of diagnosis. In one of my recent unvaccinated cases there were only two pocks, which, however, were typical, and I have seen one case of unmodified small-pox abort just like a modified one. Jenner, in the record of his experience, mentions that he knew of a district assailed by small-pox where the cases were so mild that children were brought from neighbouring places that they mioht have the disease in the same form. Still it remains that the amelioration produced by vaccination is not an unmixed advantage.

oldham.

\section{SEVERE ERUPTION OF BILATERAL HERPES OPHTHALMICUS,}

OCCURRING IN THE COURSE OF $\Lambda$ CASE OF CHRONIC PNEU. MONIA, WITH DIFFUSE INTERSTITIAL NEPHRITIS.

BY WM. ROBERTSON, M.D.,

SURGEON TO THE THROAT AND EAR HOSPITAL, NEWCASTLE-ON-TYNE

BRIEFLY stated, the history of the case previously to the appearance of eruption is as follows.

M. M-, aged sixty-two, a tall bony man, had only passed through one serious illness, and that was an attack of pleurisy of the left side previously to the present attack. Fifteen years ago his life was refused by an insurance company on account of heart disease, but beyond one or two fainting attacks he betrayed no serious symptoms of cardiac affection. The only other point attracting attention was an undue somnolence, which became overpowering when he was at rest, as for example, going to sleep in tram-cars and when at leisure at home. Habits : total abstainer ; diet principally milk and farinaceous food. The present illness was no doubt induced while assisting his men at the repair of an

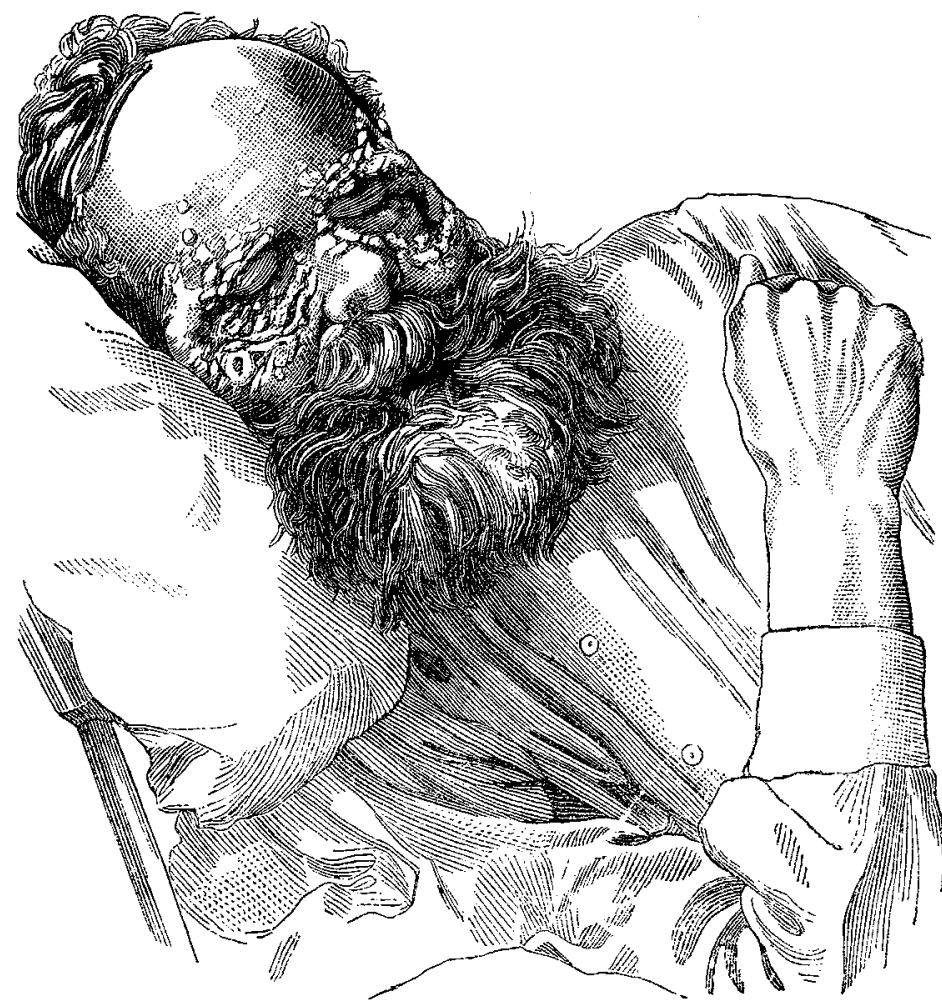

old foul drain, during which he got heated and exhausted, and while in this condition lay down on the grass to rest. Languor, debility, fever, and want of appetite supervened, and after fourteen days' suffering from these I saw the case. The house in which he lived was, besides, in an insanitary condition.

On examination, I found a morning temperature of $101^{\circ} \mathrm{F}$, rising to $102^{\circ}$ in the evening. There was, besides, slightly inmpaired resonance, with weak respiratory murmur over the right base. Urine 30 oz. ; sp. gr. 1010 ; slight cloudy precipitate. Heart : a mitral systolic murmur, slight in character, as first noticed. Pulse 78, soft and regular. Stools semi-consistent, and of bad odour. Gurgling could be elicited in the right iliac fossa, while the abdomen was slightly distended.

Without much variation these symptoms, in spite of various forms of treatment, continued. The cardiac nurmur became intensified, granular casts began to appear in the urine, with an increase in the albumen, and the patient showed an increased amount of lethargy. Sciatic and other pains caused considerable exhaustion. Quinine, sulphocarbolate of soda, antifebrin, digitalis, \&c., were all in turn sufficiently tried, but withont much benefit. The appetite meanwhile was such as to keep up fair nutrition. After 
three months of such symptoms, associated with slight feelings of chill, a herpetic eruption appeared, ushered in quietly, and without pain or much itching. The vesicles appeared in a thickly-set patch under each eye, extending to the external canthus and internally well up the bridge of the nose on each side; round the palpebral margins, amongst the cilia, and thickly set on each eyebrow; several on each frontal region; several vesicles belind each ear; three on the right helix and over the upper lip ; one on the nose over the bridge, and one on the right side of the tip of the nose. There was soon associated with the specific eruption considerable cutaneous disturbance, with swelling of the eyelids to absolute closure. The eruption was characterised by the usual multiformity of the herpetic lesion-here vesicular, there bullous, and again pustular; all present simultaneously. The eruption under the lower lids and on the eyebrows broke down on the third day with the formation of foul ulcers discharging freely. These had fairly cleared by the fifth or sixth day, exposing corium papillæ. Throughout the attack no ocular symptoms of any gravity appeared. The conjunctivæ became suffused slightly. Vision and tension and sensation of the eyeballs remained normal throughout the attack. This lasted in all about three weeks, the only traces of its presence afterwards being a rugged scaly state of the cuticle under each eye. During the attack the patient's condition underwent very little change. In the succeeding week, however, uncontrollable hiccough, with rigors, occurring nightly, set in, the temperature rising from $102^{\circ}$ to $103^{\circ}$. The albumen in the urine in creased in quantity, being 35 oz; sp. gr. 1010 ; granular casts. Shortly afterwards vomiting became a constant symptom, and shortly terminated the case.

Remarks.-The post-mortem examination generally bore out the diagnosis which heads the article, and was conducted by Dr. Drummond of Newcastle, who kindly saw the case with me once or twice during its progress. As to the eruption, the clustering together of the vesicles into groups, and its appearance on other parts in the course of the nerve distribution, all so characteristic of herpes, established the diagnosis at the onset. Subsequently viewing the lesions when the vesicles became confluent, purulent, and broken down, leaving large freely discharging ulcers under the eyes and on the upper orbital boundaries, a lifferent opinion might have been formed. This, with the extreme swelling of the lids, presented a close resemblance to erysipelas. The striking features of course were the bilateral occurrence of the eruption and the absence of any serious ocular sympathy in the process from first to last. Mr. Hutchinson states that the severity of the disease is in proportion to that with which the tip of the nose was affected; and if the disease occurred in the latter situation the eye suffered. It will have been observed from the above account that the ophthalmic nerve in all its terminal branches was affected-viz., the lacrymal, the frontal (supra-trochlear), and the oculo-nasal ; of the superior maxillary nerve, the inferior palpebral, the lateral nasal, and the superior labial branches were affected; and of the inferior maxillary nerve the auriculo-temporal suffered in its branches behind the ear. As previously stated, the eyeball remained perfectly normal throughout, during the weeks the patient survived, after the attack of herpes had entirely disappeared. At no timewas vision at fault; the cornex remained perfectly clear, with normal tension of globes.

Neweastle-on-Tyne.

The Mothers' Lying-IN Home, Shadwell.This institution, established about four years ago by Mrs. Ashton Warner, recently held its annual meeting of oovernors. The Earl of Meath presided. Since the opening of the Home, 405 patients had been registered, and 327 admitted and discharged well. During the past year, 103 mothers were treated with satisfactory results. The expenditure amounted to $\$ 810 \quad 11 s$. $2 d$. The present limited accommodation was represented as quite inadequate to meet the increasing demands upon the Home, and necessitated its periodical closing at intervals for sanitary requirements.

Polltion of the Thames. - The Chertsey Rural Sanitary Authority were on Wednesday, at the Petty Sessions, fined $t 50$ and ten guineas costs for suffering pollnted matter to flow in to a tributary of the River Thames at Chertsey, and $f 5$ in respect of a similar offence committed at Addlestone.

\section{olintal alotes:}

\section{MEDICAL， SURGICAL，OBSTETRICAL，AND THERAPEUTICAL.}

\section{REMOVAL OF THREE INTRA-UTERINE FIBROIDS BY ENUCLEATION.}

By D. MacGregor, M.A., M.D. EdiN.

AN urgent summons to attend Mrs. $R$ - reached me on March 30th of this year. Flooding had suddenly become alarming, and the patient fainted: She is aged forty-seven, the wife of a farm servant, and the mother of six children, four of whom are adults. She is a thin, anxmic-looking woman. For the past two years menstruation had been irregular, occurring on an average once in three months. At these periods she lost much blood and suffered pain. During the two years she had also had difficulty and pain in both defecation and micturition : bowels constipated; micturition frequent. The patient attributed these symptoms to "change of life." Family history unimportant.

I found the patient in bed, blanched and weak. On abdominal palpation there was found a central tumour reaching from the pubes to the umbilicus; the tumour was only slightly painful to the tonch, and appeared to be uterine. The abdominal superficial veins were distended. On examination per vaginam, there was felt a smooth globular tumour, large enough to fill the hollow of a hand. The os uteri was widely dilated, and the tumour protruded into the vaginal canal. The tumour was sessile, and was continuous with the posterior lip of the cervix and with the posterior uterine wall. The attachment was extensive. The uterine sound entered the uterus to the extent of six inches and a half; and there seemed to be an impediment, overcome only by some manœuvring after the sound had entered two inches. Ergot, nux vomica, iron, and opium were administered, the vagina was plugged, absolute rest enjoined, and the patient given the most nutritious diet. As soon as the plug was removed hamorrhage recurred. It was evident that an operation was the only safe course; and the method of enucleation was adopted on the suggestion of my friend Dr. Mitchell Penman, who saw the patient with me.

On April 26th, Dr. Penman having administered chloroform, and the patient having been put in the lithotomy position opposite the only window in the room (in patient's own house), I seized and drew down the tumour with a vulsellum, slit the capsule, and proceeded to enucleate. The process of enucleation was found tiresome to the finger, and we found it convenient to relieve each other; after enucleating as far as possible, separation of the tumour was effected by arulsion. After the first tumour was removed another appeared, and after the removal of this a third presented itself. The three tumours having been removed, the capsule treated, and the uterus washed out, the patient was removed to bed. There was no hremorrhage. The time that elapsed from the moment the patient was placed on the operating table until she was again in bed was forty-five minutes. On the evening of operation the temperature was $103^{\circ} \mathrm{F}$., and the pulse 100 ; and a sharp attack of bronchitis, to which the patient is subject, kept the temperature somewhat above normal for the first eight or nine days. On the subsidence of the bronchitic attack the patient made rapid progress. She now (May 20th) takes open-air exercise on foot daily, and feels in every respect well. The three tumours together weighed twenty-eight ounces; the measurements, in order of their presentation, were six inches by three, seven and a half inches by four, and six inches by three and a half.

Denholm, Hawick, N.B.

\section{NOTES ON A}

\section{CASE OF POISONING BY HYDROCYANIC ACID.}

\section{BY E. M. Garstang, M.R.C.S., L.R.C.P. Edin.}

ON July 29th, 1887, I was ealled in haste to Miss B-, fifty-eight vears of age, who was reported to have been suddenly seized with apoplexy. I saw her about $9.25 \mathrm{~A} . \mathrm{M}$., and found her perfectly insensible; breathing stertorous and irregular; severe twitchings of face; eyes directed 